University of Nebraska - Lincoln

DigitalCommons@University of Nebraska - Lincoln

Faculty Publications: Department of

Entomology

Entomology, Department of

2008

Concentration-Dependent Degradation of Three Termiticides in

Soil Under Laboratory Conditions and Their Bioavailability to

Eastern Subterranean Termites (Isoptera: Rhinotermitidae)

Raj K. Saran

McLaughlin Gormley King Company, raj.saran@mgk.com

Shripat T. Kamble

Universitiy of Nebraska--Lincoln, skamble1@unl.edu

Follow this and additional works at: https://digitalcommons.unl.edu/entomologyfacpub

Part of the Entomology Commons

Saran, Raj K. and Kamble, Shripat T., "Concentration-Dependent Degradation of Three Termiticides in Soil Under Laboratory Conditions and Their Bioavailability to Eastern Subterranean Termites (Isoptera: Rhinotermitidae)" (2008). Faculty Publications: Department of Entomology. 315.

https://digitalcommons.unl.edu/entomologyfacpub/315

This Article is brought to you for free and open access by the Entomology, Department of at DigitalCommons@University of Nebraska - Lincoln. It has been accepted for inclusion in Faculty Publications: Department of Entomology by an authorized administrator of DigitalCommons@University of Nebraska - Lincoln. 


\title{
Concentration-Dependent Degradation of Three Termiticides in Soil Under Laboratory Conditions and Their Bioavailability to Eastern Subterranean Termites (Isoptera: Rhinotermitidae)
}

\author{
RAJ K. SARAN ${ }^{1}$ AND SHRIPAT T. KAMBLE ${ }^{2}$
}

\begin{abstract}
J. Econ. Entomol. 101(4): 1373-1383 (2008)
ABSTRACT Degradation and bioavailability of imidacloprid, fipronil, and bifenthrin applied at label rates ([AI], wt:wt in soil) in the loamy soil of Nebraska were determined over a 6-mo duration. Based on the calculated half-lives of the three termiticides, it was concluded that the degradation rate was lowest when a termiticide was applied at the highest label rate. Bioassays of Reticulitermes flavipes (Kollar) (Isoptera: Rhinotermitidae) conducted at 8, 31, 65, 90, 135, 160, and $180 \mathrm{~d}$ posttreatment showed an inverse relationship between the $\mathrm{LT}_{90}$ values and the variable concentrations. At day 180 , exposures to all the termiticide-treated soil samples (concentration $\times$ termiticide) resulted in 100\% mortality of $R$. Alavipes workers. However, lower $\mathrm{LT}_{90}$ values were observed for termites exposed to soils treated with highest label rates even when the treated soils were aged in the lab for 6 mo. This suggested a higher bioavailability of these three termiticides when applied at higher application rates. Termite mortality was fastest for bifenthrin followed by fipronil and imidacloprid.
\end{abstract}

KEY WORDS toxicity, bifenthrin, fipronil, imidacloprid, half-life

For more than six decades, treatment of soil with termiticide has been the conventional technique for the control of subterranean termites (Su and Scheffrahn 1998). In majority of cases (two-thirds), pest control companies use termiticides instead of baits and wood treatments in preventing and controlling termite damage (Curl 2004). In recent years, insecticides such as chloronicotinyl (imidacloprid), neonicotinoid (thiamethoxam), phenyl pyrazole (fipronil), and pyrole (chlorfenapyr) have become popular alternatives to organophosphates and pyrethroids. These compounds are less hazardous than chlorinated hydrocarbons and organophosphates and have a limited life in soil. These compounds were reported to be nonrepellent and slow acting (Shelton and Grace 2003, Ibrahim et al. 2003, Remmen and Su 2005a, 2005b; Saran and Rust 2007). It has been suggested that due to this nonrepellency and delayed toxicity, exposed foraging termites transfer lethal amounts to nestmates. These termiticides are considered to be more effective in controlling termites by killing them some distances away from the treated structures (Potter and Hillery 2002). However, recent studies have shown that the extent of horizontal transfer of termiticide among foragers was limited to 5-6 $\mathrm{m}$ from the treated barrier (Osbrink et al. 2005, Su 2005, Rust and Saran 2006, Saran and Rust 2007). Thus, the residual amounts and

\footnotetext{
${ }^{1}$ Corresponding author and current address: McLaughlin Gormley King Company, 8810 Tenth Ave. North, Minneapolis, MN 55427 (e-mail: raj.saran@mgk.com).

${ }^{2}$ Department of Entomology, University of Nebraska, Lincoln, NE 68583-0816.
}

bioavailability of termiticides over time may be the primary factors contributing to the termiticide efficacy in soil. Studies with other soil insects have indicated that soil type, soil $\mathrm{pH}$, insecticide type, moisture, temperature, microbial communities, and target insect affect insecticide degradation, bioavailability, and its efficacy in the soil (Harris 1972, Tashiro and Khur 1978, Chapman et al. 1982, Macalady and Wolfe 1983, Felsot and Lew 1989).

Su et al. (1993) and Gold et al. (1994) reported that termiticides loose effectiveness over time. Gold et al. (1996) further showed differences in termiticide concentrations through time, indicating that within $180 \mathrm{~d}$, all termiticides (chlorpyriphos, imidacloprid, and deltamethrin) included in the tests had significantly decreased in concentration (wt:wt basis in soil). Austin (1999) has demonstrated that exposure to chlorpyrifos, deltamethrin, and imidacloprid and subsequent mortality of the eastern subterranean termite, Reticulitermes flavipes (Kollar) (Isoptera: Rhinotermitidae) were affected by soil type. Also, the initial concentration at which the termiticides were applied affected degradation rate. Chlorpyrifos exhibited lower degradation rate when applied at $\approx 1,000 \mu \mathrm{g} / \mathrm{g}$ soil than when applied at typical agricultural levels of 0.3-32 $\mu \mathrm{g} / \mathrm{g}$ soil (Racke et al. 1994).

Currently registered termiticides have soil organic partition coefficients values $\left(K_{\mathrm{oc}}\right)$, which place them in the immobile classification, implying they do not readily leach through the soil profile (Helling and Turner 1970, McCall et al. 1979). This indicates the potential for interactions between these compounds 
and components of the soil matrix that may affect the biological activity of these insecticides (Forschler and Townsend 1996).

Bioavailability of the chemical has two components. The first is availability to the insects in the soil. The second component is due to the physical distribution of a compound in the soil after initial application. Therefore, the efficacy of an insecticide in soil is governed by the intrinsic toxicity of an insecticide, its ability to penetrate into the insect, and its bioavailability (Simmons et al. 1992). A compound may be present in the soil well above detection limits but not be available to insects in a sufficient quantity to control them.

Variable application rates for termiticides are meant to accommodate a wide range of environmental conditions (soil type, $\mathrm{pH}$, and soil moisture content), and they are presumably based on the physiochemical properties of the termiticides. However, applicators in real-life situations are often confused about application rates, and some opt for lower doses to reduce costs. But when applied at lowest recommended rates, failures of termite treatments are common and the durability of treatments is often reduced. However, little is known about the degradation and bioavailability of fipronil, bifenthrin, and imidacloprid over time when applied to the soil as a termiticide at different application rates.

We proposed a hypothesis that the half-life of termiticides (calculated from degradation rates) in soil is dependent on the applied concentrations. Also, the toxicity of termiticides is correlated to their bioavailability over time in soil. This laboratory study was conducted to predict the effect of application rates on termiticides efficacy in soil over time. Experiments were designed to address the following objectives: 1) determine half-lives of termiticides, applied at various concentrations in similar soil type and environmental conditions; and 2) evaluate the toxicity and bioavailability of termiticides to eastern subterranean termite over time.

\section{Materials and Methods}

Termites. Eastern subterranean termites were collected from infested logs (Pinus sp.) in Henderson, NE (50 km west of Lincoln, NE). Termites were identified using morphological keys for soldiers and workers (Snyder 1954). Termites were maintained in the dark at $25^{\circ} \mathrm{C}$ in 60 - by 15 - by 30 -cm glass aquaria containing 7- by 3 - by 1 -cm wood blocks of white pine (Pinus alba L.). Undifferentiated termite workers were used for bioassays.

Soil and Soil Analysis. In spring 2000, soil representing a residential area was collected near Lincoln, NE. For analysis, soil (500 g) was pulverized and passed through a $2-\mathrm{mm}$ sieve and autoclaved $(1 \mathrm{~h}$ at $120^{\circ} \mathrm{C}$ and 1 atmosphere) on two successive days. Soil was analyzed for particle size, $\mathrm{pH}$, organic matter content, cation exchange capacity (CEC), phosphorous (Bray-1), and potassium by the Soil and Plant
Analytical Laboratory, Department of Agronomy and Horticulture, University of Nebraska, Lincoln, NE.

Termiticides. Termiticides representing three chemical classes were selected as follows: 1) chloronicotinyl (imidacloprid, Premise), 2) phenyl pyrazole (fipronil, Termidor, and 3) pyrethroid (bifenthrin, Talstar). Formulated products Premise 75 WSP (Bayer Environmental Science, Research Triangle Park, NC), Termidor 9.1\% SC (BASF Corporation, Research Triangle Park, NC), and Talstar 7.91\% SC (FMC Corporation, Philadelphia, PA) were purchased form a local distributor. Technical grade imidacloprid, fipronil, and bifenthrin were purchased from Chem Service Inc. (West Chester, PA).

Treatments. Termiticides were applied to $400 \mathrm{~g}$ of soil (passed through a 2-mm sieve) and stored in 1.89-liter Ziploc bags (S. C. Johnson, Inc., Racine, WI). Soil aliquots were previously weighed on an ovendried basis and adjusted to $10 \%$ moisture content. Stock solutions in deionized distilled water $(1,000 \mathrm{ml})$ were prepared for each termiticide (formulated product). A required amount of stock solution was added to $500 \mathrm{ml}$ of deionized water such that when applied to $400 \mathrm{~g}$ of soil in bags it provided the desired concentration (w:w) of active ingredient (AI). Three insecticide concentrations (low, medium, and high) were used for each termiticide. Imidacloprid was applied at 50, 75, and $100 \mu \mathrm{g}$ (AI)/g soil; fipronil at 60 , 95 , and $125 \mu \mathrm{g}(\mathrm{AI}) / \mathrm{g}$ soil; and bifenthrin at 60,90 , and $120 \mu \mathrm{g}$ (AI)/g soil. Four replications were used for each concentration. For controls (untreated checks), 400 -g soil samples were treated with $500 \mathrm{ml}$ of deionized water alone.

Treated soil samples in Ziploc bags were allowed to air-dry in a fume hood overnight $(\approx 12 \mathrm{~h})$ and moisture was adjusted to $25 \% \pm 1.2$. Soils were maintained at $25 \pm 2^{\circ} \mathrm{C}$ and $98.0 \pm 3.2 \% \mathrm{RH}$ in growth chambers (Percival Scientific, Boone, IA). Temperature and humidity data were collected using a Traceable hygrometer/thermometer (model 11-66-21, Hart Scientific, Friendwood, TX). Deionized water $(5-10 \mathrm{ml})$ was sprinkled on the samples once a week to maintain $\approx 25 \%$ soil moisture content. At $0,8,31,65,90,135,150$, and $180 \mathrm{~d}$, the soil was thoroughly mixed, and a $10 \mathrm{-g}$ soil was randomly sampled from treated lots and controls for chemical analysis.

Sample Preparation, Extraction and Analysis of Termiticides. Using the extraction procedure of Steinwandter (1992), $10 \mathrm{~g}$ of soil was placed in 125-ml Erlenmeyer flasks. Forty milliliters of high-performance liquid chromatography (HPLC) grade acetonitrile was added to each soil sample, and the flasks were stoppered and placed in an incubator/shaker (G25-KLC, New Brunswick, Edison, NJ) maintained at $20^{\circ} \mathrm{C}$ and agitated overnight $(\approx 12 \mathrm{~h})$ at $250 \mathrm{rpm}$. The samples were allowed to stand for $1 \mathrm{~h}$ so as to allow soil particles to settle. A $1.5 \mathrm{ml}$ of the clear supernatant was transferred to a 2.0-ml microcentrifuge tube. Aliquots were centrifuged at $12,000 \times g$ for $20 \mathrm{~min}$, and supernatants were transferred into a new $2.0-\mathrm{ml}$ microcentrifuge tube after passing through a 3-cc glass syringe equipped with a $0.2-\mu \mathrm{m}$ Acrodisc CR PTFE syringe 
filter (Pall Corporation, East Hills, NY). Finally, $1 \mathrm{ml}$ of the solution from each microcentrifuge tube was pipetted into a 2.0-ml auto-injector vial, sealed with a PTFE lined screw cap (Varian Inc., Walnut Creek, CA). Samples were analyzed soon after extraction, and unused vials were stored at $-20^{\circ} \mathrm{C}$ until analysis. Standard curves for each of the termiticide were prepared using serially diluted stock solutions $1,000,1,250$, and 1,200 ppm (wt:vol) of technical grade imidacloprid, fipronil, and bifenthrin in acetone, respectively.

Three extracted termiticides were analyzed separately using HPLC (Varian 9012 pump, 9050 variable length detector UV/VIS, and 9100 autosampler). Data collection and peak analyses were performed using Varian Star version 4.5 chromatography workstation connected to a computer. For imidacloprid, a mobile phase 70:30 (water:acetonitrile) under isocratic conditions at a flow rate of $1.0 \mathrm{ml} / \mathrm{min}$ was used. A reverse phase C18 column $(250-\times 4.6 \mathrm{~mm}$ i.d.; 5 - $\mu \mathrm{m}$ particle size; Luna Phenomenex, Torrance, CA) was used. The UV/VIS detector was set at $(\lambda) 270 \mathrm{~nm}$, as described by Placke and Weber (1993) and Baskaran et al. (1999). For fipronil, a methanol:water gradient (78: 22-72:28 over $12 \mathrm{~min}$ ) with $1.0 \mathrm{ml} / \mathrm{min}$ flow rate was used to separate fipronil from the sulfone metabolite (Hainzl and Casida 1996) and the detector UV/VIS was set at $280 \mathrm{~nm}$. A reverse phase C18 column (250 by $4.6 \mathrm{~mm}$ i.d., $5-\mu \mathrm{m}$ particle size; Luna Phenomenex) was used. Bifenthrin samples were analyzed using a reverse phase Luna C18 column ( 150 by $4.6 \mathrm{~mm}$ i.d., 5 - $\mu$ m particle size; Luna Phenomenex). Mobile phase was acetonitrile:water (95:5) at a flow rate of $1.0 \mathrm{ml} /$ min under isocratic conditions. UV/VIS detector was set at $204 \mathrm{~nm}$.

Using these extraction procedures and analysis conditions, the method sensitivity for all the three termiticides was $\approx 0.5 \mathrm{mg} / \mathrm{kg}$ or $\approx 100$-fold lower than lowest application rate.

Extraction Efficiency and Recovery Rate. To determine the extraction efficiency and analytical quality control, recovery tests were performed for each of the insecticides, at each sampling interval. A 100-ml solution (in acetone) of the technical grade termiticide was added to an 80-g sterilized soil sample. The final concentration of each termiticide in 80-g soil samples was $100 \mathrm{ppm}$ ([AI], wt:wt). The acetone was allowed to evaporate overnight in a fume hood. The treated soil was then stored in $50-\mathrm{ml}$ centrifuge tubes ( 30 by 11.5 cm Falcon, BD Biosciences, Franklin Lakes, NJ). Soil moisture content was adjusted to $25 \%$ by adding deionized water. These tubes were then stored at $0^{\circ} \mathrm{C}$ to prevent further degradation. Five replications per treatment were made. On each sampling day of the degradation study, $10 \mathrm{~g}$ of soil samples were used for residual analysis and to determine percentage of recovery. Analytical results of insecticides were finally corrected for recovery efficiency determined at each sampling interval. An external standard was used for confirmation and calculation of the total residue because of its accuracy and reproducibility (Poole and Poole 1997).
Degradation Rates and Half-Life of Termiticides. A half-life model, previously described by Su et al. (1999), $\mathrm{C}_{\mathrm{t}}=\mathrm{C}_{0} \times(0.5)^{(\mathrm{t} / \mathrm{k})}$ was used to estimate the degradation rate $(k)$ of each termiticide in treated soil at different concentrations, where $C_{t}$ is termiticide concentration at time $t, \mathrm{C}_{0}$ is initial concentration, and $k$ is half-life index or time required for $50 \%$ termiticide degradation. The model was linearized by taking natural $\log$ arithm, $\ln \mathrm{C}_{\mathrm{t}}=$ $\ln \mathrm{C}_{0}+(t / k) \times \ln (0.5)$ or $\mathrm{Y}=\mathrm{A}+\mathrm{B} \times t$, where $\mathrm{Y}=$ $\ln \mathrm{C}_{\mathrm{t}}, \mathrm{B}=[\ln (0.5)] /_{k}$, and $\mathrm{A}=\ln \mathrm{C}_{0}$. A linear regression (SAS Institute 2000) was used to estimate the slope parameter B and associated variance, $\operatorname{Var}(\mathrm{B})$. A half-life index, $k$, was calculated for each termiticide concentration by using estimated $\mathrm{B}, k=[\ln (0.5)] / \mathrm{B}$, and variance associated with $k$, $\operatorname{Var}(k)=\left\{[\ln (0.5)]^{2} \mathbf{B}^{4}\right\} \times \operatorname{Var}(\mathbf{B})$, from the variance propagation theorem. Because $k$ and $\mathrm{B}$ were mathematically related, two half-life indices, $k_{1}$ and $k_{2}$, were compared if the corresponding slopes, $\mathbf{B}_{1}$ and $\mathbf{B}_{2}$, were different. All pairwise comparisons of slopes (B) estimated from samples collected from each soiltermiticide concentration combination was based on the standard normal distribution: $\mathrm{Z}=\mathrm{B}_{1}-\mathrm{B}_{2} / \mathrm{V} \operatorname{Var}\left(\mathrm{B}_{1}\right)$ $+\left(\mathrm{B}_{2}\right)$. The two slopes (and hence the two half-life indices) were different at $\alpha=0.05$ when $\mathrm{Z}>1.96$.

Lethal Times $\left(\mathbf{L T}_{50}\right.$ and $\left.\mathbf{L T}_{\mathbf{9 0}}\right)$ and Bioavailability of Termiticides. At each time interval, $10 \mathrm{~g}$ of treated soil sample was transferred to petri dishes $(5.0 \mathrm{~cm}$ in diameter). Twenty worker termites were placed into these petri dishes containing five-mm-diameter moistened filter paper disks (Whatman No. 1) as a food source. Dead termites were removed from the petri dishes at intervals of $2,4,6,8,12,16,20$, and $24 \mathrm{~h}$. The experimental units were held in constant darkness at $28 \pm 1^{\circ} \mathrm{C}$ and $100 \% \mathrm{RH}$. Exposure of termite workers to untreated soil served as control.

Data Analysis. Difference between degradation slopes and concentration data were analyzed using analysis of variance (ANOVA) and PROC GLM (SAS Institute 2000). PROC MIXED Procedure was used to determine the interaction among residues using $\mathrm{LT}_{90}$ values. Fisher's least significant difference (LSD) was used to test significant differences among the means whenever $F$ values were significant. Linear regression for determination of termiticide half-life was performed using PROC REG (SAS Institute 2000). PROC GLM models procedure was used to compare the slopes of the three different termiticides when applied at three different concentrations and also the interaction between the concentrations and insecticides. Time $\times$ dose-response data were analyzed for each concentration by PROC LIFEREG procedure (SAS Institute 2000). This model provided a better fit for the $\mathrm{LT}_{50}$ and $\mathrm{LT}_{90}$ values on the observed value, compared with the PROBIT $_{10}$ procedure.

\section{Results}

Soil Analysis. Based on the elemental and particle size analysis, the soil used in this study was classified as loam (Kamble and Saran 2005). The soil sample was a mix of top layer $(18 \mathrm{~cm})$ of soil with $0.91 \%$ organic matter, $25.9 \%$ sand, $26.7 \%$ clay, coarse silt 23.1 , fine silt 19.8 , and $4.4 \%$ 
Table 1. Degradation slopes and calculated half-lives (based on regression equations) for three termiticides used at three different concentrations in the study

\begin{tabular}{lcc}
\hline \hline Termiticide & $\begin{array}{c}\text { Concn } \\
(\mu \mathrm{g} / \mathrm{g} \text { soil })\end{array}$ & $\begin{array}{c}\text { Half-life } \\
( \pm \mathrm{SE})^{a}(\mathrm{~d})\end{array}$ \\
\hline Imidacloprid & 50 & $166.64 \pm 3.44 \mathrm{a}$ \\
& 75 & $210.09 \pm 2.28 \mathrm{~b}$ \\
Fipronil & 100 & $280.98 \pm 4.35 \mathrm{c}$ \\
& 60 & $223.12 \pm 4.45 \mathrm{~b}$ \\
Bifenthrin & 95 & $364.74 \pm 3.18 \mathrm{~cd}$ \\
& 125 & $544.18 \pm 4.71 \mathrm{~d}$ \\
& 60 & $213.67 \pm 3.30 \mathrm{~b}$ \\
& 90 & $298.17 \pm 2.50 \mathrm{c}$ \\
& 120 & $433.97 \pm 4.71 \mathrm{~d}$ \\
\hline
\end{tabular}

Within a column, numbers followed by same letters are not sig nificantly different at $\alpha=0.05$.

${ }^{a}$ Half-lives are estimates based on the degradation patterns during $180 \mathrm{~d}$ in a laboratory study.

very fine silt. The cation exchange capacity (CEC) was $22.8 \mathrm{Cmol} / \mathrm{kg}$ and $\mathrm{pH}$ was 7.0. The average percentage water content $(\% \pm \mathrm{SD})$ for the soil samples used in these experiments was $8.1 \pm 0.5$ and contained $17.2 \mathrm{ppm}$ phosphorus $(\mathrm{P})$ and $178.0 \mathrm{ppm}$ potassium $(\mathrm{K})$.

Termiticide Behavior in Soil. Time (days after treatment) had a significant effect on the amount of imidacloprid recovered at each sampling interval $(F=$ $370.33 ; \mathrm{df}=7,72 ; P<0.001)$. Initial concentrations of imidacloprid applied to soil had a significant effect on the amount of residue recovered ( $F=335.79$; $\mathrm{df}=2$, $72 ; P<0.001)$. There was a significant interaction between the time (in days) after the treatment and concentration applied $(F=4.97$; $\mathrm{df}=14,72 ; P<$ $0.001)$.

There were significant differences for both the days after treatment $(F=13337.03$; df $=7,72 ; P<0.001)$ and concentrations of fipronil applied to soil ( $F=$ 11430.1; df $=2,72 ; P<0.001)$. There was a significant interaction between the days after treatment and initial concentration at which fipronil was applied to the soil $(F=70.94$; df $=14,72 ; P<0.001)$.

For bifenthrin, days after treatment had a significant effect on the amount of residue recovered at different sampling intervals $(F=2167$; df $=7,72 ; P<0.001)$. Residues recovered also were dependent upon initial concentrations of bifenthrin applied to soil ( $F=17742$; $\mathrm{df}=2,72 ; P<0.001)$. There was a significant interaction between the days after treatment and concentration of bifenthrin initially applied to the soil ( $F=$ 78.02; df $=14,72 ; P<0.001)$.

Extraction Efficiency and Recovery Rate. Mean recovery rate $(\% \pm \mathrm{SD})$ of imidacloprid, fipronil, and bifenthrin was $87.18 \pm 0.25,94.01 \pm 0.1$, and $98.0 \pm 0.3$, respectively. The recovery rate of the imidacloprid, fipronil, and bifenthrin, calculated at different time intervals $(0,65,135$, and $180 \mathrm{~d}$ after application), remained unaffected.

Degradation and Half-Life of Termiticides. Halflives for each termiticide (Table 1) were calculated based on the slopes of regression equations in Figs. 1-3. The calculated half-life for each concentration applied was longer than the incubation period ( $180 \mathrm{~d}$ ); therefore, these half-lives were only the estimates.

Significant differences were observed among the regression slopes of all the three termiticides at the applied concentrations $(F=123.96$; $\mathrm{df}=2,8 ; P<$ $0.001)$, suggesting that the degradation rates of the different insecticides in the treated soil were different at different applied concentrations. For imidacloprid, fipronil, and bifenthrin, applied at different rates, significant differences were observed among the regres-

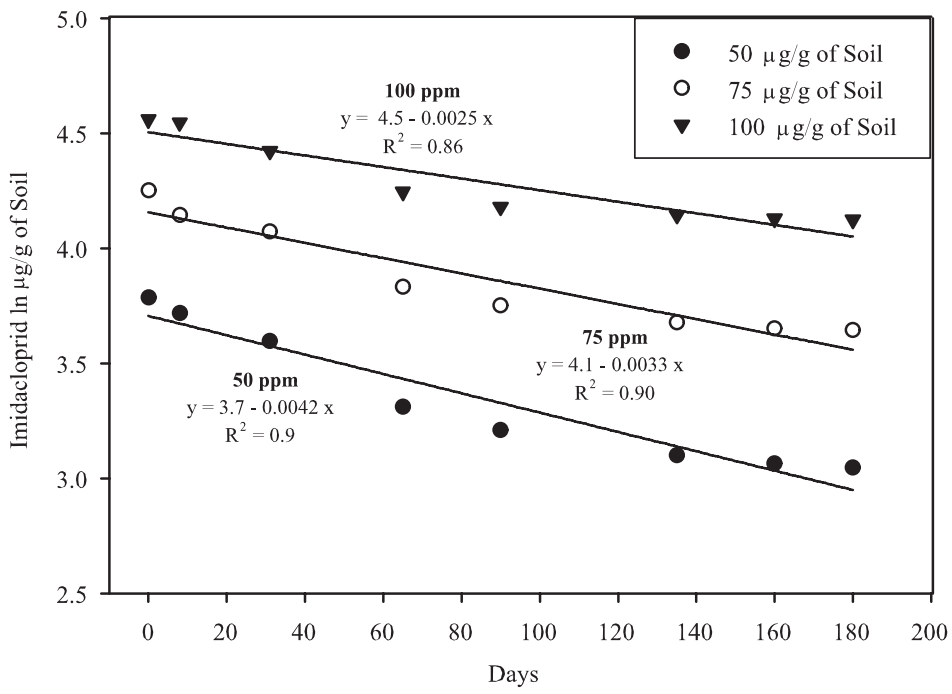

Fig. 1. Imidacloprid degradation curves for different concentrations based on the amount of imidacloprid recovered from the soil samples on different sampling intervals from 0 to $180 \mathrm{~d}$. The regression between time (days after treatment) and amount recovered (micrograms per gram of soil) for different concentrations are provided next to each regression line: 50 ppm: $R^{2}=0.92, F=71.5, \mathrm{df}=1,6, P<0.001 ; 75 \mathrm{ppm}: R^{2}=0.90, F=54.0, \mathrm{df}=1,6, P<0.001 ;$ and $100 \mathrm{ppm}: R^{2}=0.86, F=$ $39.9, \mathrm{df}=1,6, P<0.001$. 


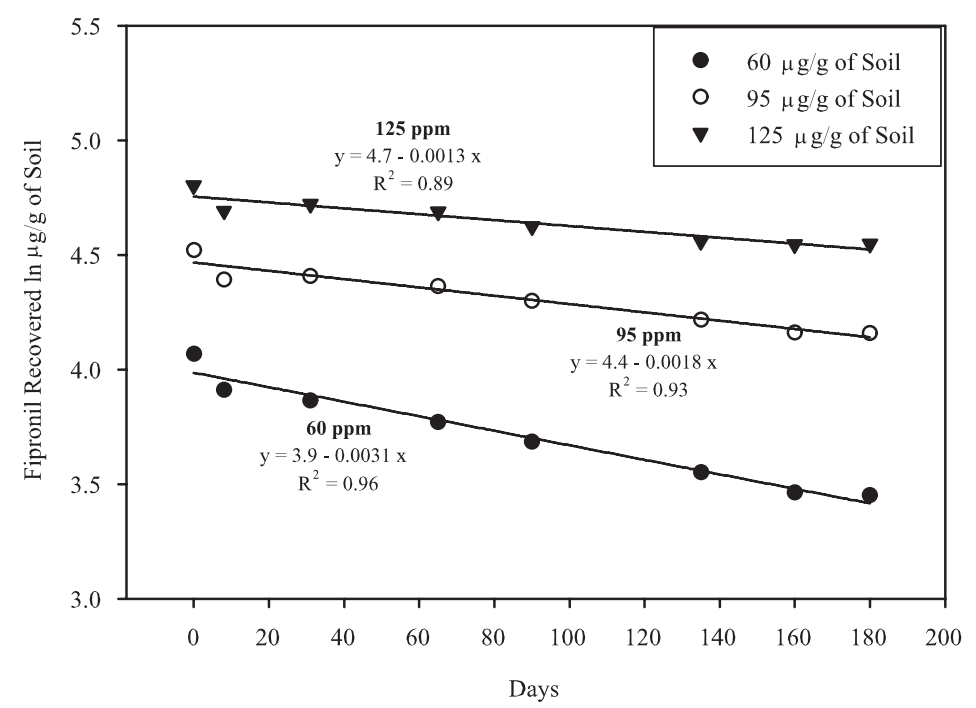

Fig. 2. Fipronil degradation curves for different concentrations based on the amount of imidacloprid recovered from the soil samples on different sampling intervals from 0 to $180 \mathrm{~d}$. The regression between time (days after treatment) and amount recovered (micrograms per gram of soil) for different concentrations are provided next to each regression line: $60 \mathrm{ppm}: R^{2}=$ $0.96, F=1161.7 .5, \mathrm{df}=1,6, P<0.001 ; 95 \mathrm{ppm}: R^{2}=0.93, F=1257.1, \mathrm{df}=1,6, P<0.001 ;$ and $125 \mathrm{ppm}: R^{2}=0.89, F=255.2$, $\mathrm{df}=1,6, P<0.001$

sion slopes of residues recovered for each insecticide concentration, imidacliprod $(F=65.87 ; \mathrm{df}=2,9 ; P<$ $0.001)$, fipronil $(F=123.77 ; \mathrm{df}=2,9 ; P<0.001)$, and bifenthrin $(F=209.55$; $\mathrm{df}=2,9 ; P<0.001)$.

Overall comparisons of the mean degradation rates of the three insecticides at three different concentrations, imidacloprid applied at $50 \mathrm{ppm}$ (micrograms per gram of soil) revealed significantly higher rate of degradation than any other termiticide-concentration combinations. Fipronil at 95 and $125 \mathrm{ppm}$ and bifenthrin at $120 \mathrm{ppm}$ indicated the lowest degrada- tion rates of any termiticide-concentration combinations.

Lethal Time ( $\mathbf{L T}_{50}$ and $\mathbf{L T}_{90}$ ) and Bioavailability. The lethal time values $\left(\mathrm{LT}_{50}\right.$ and $\left.\mathrm{LT}_{90}\right)$ for workers of R. flavipes exposed to soils treated with imidacloprid, fipronil, and bifenthrin at various concentrations are shown in Tables $2-4$ respectively.

For imidacloprid, significant differences were observed among the $\mathrm{LT}_{90}$ values for the sampling interval $(8,31,65,90,135,160$, and $180 \mathrm{~d}$ after initial application $)$ on which the bioassays were conducted $(F=3446.69$;

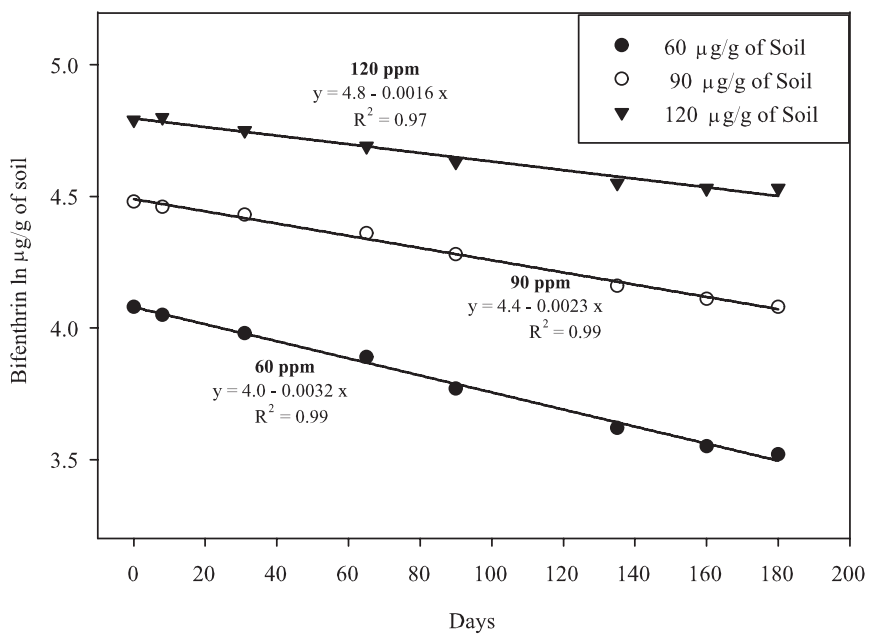

Fig. 3. Bifenthrin degradation curves for different concentrations based on the amount of imidacloprid recovered from the soil samples on different sampling intervals from 0 to $180 \mathrm{~d}$. The regression between time (days after treatment) and amount recovered (micrograms per gram of soil) for different concentrations are provided next to each regression line: 60 ppm: $R^{2}=0.99, F=1091.1, \mathrm{df}=1,6, P<0.001 ; 90 \mathrm{ppm}: R^{2}=0.99, F=895.8, \mathrm{df}=1,6, P<0.001 ;$ and $120 \mathrm{ppm}: R^{2}=0.97$, $F=250.1, \mathrm{df}=1,6, P<0.001$. 
Table 2. Toxicity of imidacloprid treated soil to termites at different time intervals over a period of $180 \mathrm{~d}$ after the initial application

\begin{tabular}{|c|c|c|c|c|c|c|c|}
\hline Termiticide & $\begin{array}{c}\text { Concn } \\
(\mu \mathrm{g} / \mathrm{g} \text { soil })\end{array}$ & DAT & $n$ & Slope \pm SE & $\mathrm{LT}_{50}(95 \% \mathrm{FL})^{2}(\mathrm{~h})$ & $\mathrm{LT}_{90}(95 \% \mathrm{FL})(\mathrm{h})$ & $\chi^{2}$ \\
\hline \multirow[t]{22}{*}{ Imidacloprid } & $50 \mathrm{ppm}$ & & & & & & \\
\hline & & 8 & 100 & $5.25 \pm 0.95$ & $15.39(12.6-18.1)$ & $21.70(19.2-24.1)$ & 195.5 \\
\hline & & 31 & 100 & $5.98 \pm 1.02$ & $16.55(13.5-19.6)$ & $23.73(21.0-26.4)$ & 184.6 \\
\hline & & 65 & 100 & $19.56 \pm 3.11$ & $36.34(26.2-46.4)$ & $59.82(51.0-68.6)$ & 89.3 \\
\hline & & 90 & 100 & $26.26 \pm 4.19$ & $48.24(34.6-61.8)$ & $79.77(68.0-91.6)$ & 87.7 \\
\hline & & 135 & 100 & $24.78 \pm 4.11$ & $58.85(46.0-72.3)$ & $88.60(77.3-99.8)$ & 134.6 \\
\hline & & 160 & 100 & $28.38 \pm 4.99$ & $78.60(63.9-93.3)$ & $112.6(99.6-125.7)$ & 176.8 \\
\hline & & 180 & 100 & $29.30 \pm 4.75$ & $90.63(76.6-104.6)$ & $125.3(113.3-138.2)$ & 268.5 \\
\hline & $75 \mathrm{ppm}$ & 8 & 100 & $6.02 \pm 1.04$ & $13.93(10.8-17.1)$ & $21.16(18.4-23.9)$ & 128.7 \\
\hline & & 31 & 100 & $6.56 \pm 1.12$ & $15.20(11.8-18.6)$ & $23.80(20.0-26.1)$ & 128.7 \\
\hline & & 65 & 100 & $17.83 \pm 2.80$ & $32.62(23.4-41.8)$ & $54.04(46.0-62.0)$ & 85.4 \\
\hline & & 90 & 100 & $23.78 \pm 3.73$ & $43.50(31.2-55.8)$ & $72.05(61.4-82.8)$ & 85.4 \\
\hline & & 135 & 100 & $23.01 \pm 3.93$ & $55.49(43.5-67.4)$ & $83.11(72.6-93.6)$ & 139.3 \\
\hline & & 160 & 100 & $25.48 \pm 4.40$ & $64.50(51.3-77.7)$ & $95.15(83.4-108.0)$ & 150.4 \\
\hline & & 180 & 100 & $31.55 \pm 5.64$ & $84.56(68.2-100.9)$ & $122.45(107.9-137.0)$ & 166.8 \\
\hline & $100 \mathrm{ppm}$ & 8 & 100 & $5.56 \pm 0.96$ & $13.22(10.3-16.1)$ & $19.90(17.3-22.4)$ & 136.0 \\
\hline & & 31 & 100 & $5.90 \pm 0.99$ & $13.43(10.3-16.5)$ & $20.52(17.8-23.2)$ & 125.1 \\
\hline & & 65 & 100 & $13.02 \pm 2.16$ & $28.05(21.3-34.8)$ & $43.68(37.8-49.6)$ & 113.8 \\
\hline & & 90 & 100 & $17.35 \pm 2.88$ & $38.59(28.8-48.4)$ & $61.30(52.7-69.8)$ & 113.8 \\
\hline & & 135 & 100 & $21.94 \pm 3.84$ & $52.86(41.5-64.2)$ & $79.02(68.8-89.2)$ & 139.1 \\
\hline & & 160 & 100 & $25.11 \pm 4.46$ & $58.67(45.6-71.7)$ & $88.82(77.2-109.6)$ & 131.4 \\
\hline & & 180 & 100 & $31.30 \pm 5.43$ & $72.10(55.9-88.3)$ & $109.69(95.3-124.0)$ & 127.5 \\
\hline
\end{tabular}

${ }^{a}$ DAT, days after treatment.

${ }^{b} 95 \%$ FL, $95 \%$ fiducial limits.

df $=6,54 ; P<0.001)$. There were significant differences in $\mathrm{LT}_{90}$ values for different concentrations $(F=74.10$; $\mathrm{df}=2,9 ; P<0.001)$. There was a significant interaction between days after treatment and initially applied concentrations $(F=18.31$; df $=12,54 ; P<0.001)$.

Time (days after treatment) had a significant effect on the $\mathrm{LT}_{90}$ values $(F=2705.19 ; \mathrm{df}=6,54 ; P<0.001)$ for fipronil. There were significant differences among the $\mathrm{LT}_{90}$ values for different applied concentrations of fipronil $(F=133.33$; $\mathrm{df}=2,9 ; P<0.001)$. There was a significant interaction between days after applica- tion and concentrations applied $(F=33.11$; $\mathrm{df}=12,54$; $P<0.001$ ).

There were significant differences among the $\mathrm{LT}_{90}$ values of bifenthrin estimated at different time intervals after initial application $(F=1583.54 ; \mathrm{df}=6,54 ; P<$ 0.001). Significant differences were observed among $\mathrm{LT}_{90}$ values of different concentrations at which the bifenthrin was applied to the soil $(F=95.54$; $\mathrm{df}=2,9 ; P<$ $0.001)$. It was observed that the sampling interval and the initially applied concentration exhibited significant interactions $(F=12.71 ; \mathrm{df}=12,54 ; P<0.001)$

Table 3. Toxicity of fipronil-treated soil to termites at different time intervals over a period of $180 \mathrm{~d}$ after the initial application

\begin{tabular}{|c|c|c|c|c|c|c|c|}
\hline Termiticide & $\begin{array}{c}\text { Concn } \\
(\mu \mathrm{g} / \mathrm{g} \text { soil })\end{array}$ & $\mathrm{DAT}^{a}$ & $n$ & Slope \pm SE & $\mathrm{LT}_{50}(95 \% \mathrm{FL})^{b}(\mathrm{~h})$ & $\begin{array}{c}\mathrm{LT}_{90}(95 \% \mathrm{FL}) \\
(\mathrm{h})\end{array}$ & $\chi^{2}$ \\
\hline \multirow[t]{21}{*}{ Fipronil } & $60 \mathrm{ppm}$ & 8 & 100 & $4.71 \pm 0.79$ & $10.67(8.2-13.1)$ & $16.33(14.2-18.5)$ & 124.5 \\
\hline & & 31 & 100 & $7.40 \pm 1.23$ & $14.61(10.7-18.4)$ & $23.51(20.2-26.7)$ & 99.2 \\
\hline & & 65 & 100 & $6.77 \pm 1.18$ & $16.97(13.4-20.4)$ & $25.0(22.0-28.2)$ & 151.1 \\
\hline & & 90 & 100 & $13.37 \pm 2.34$ & $33.90(27.0-40.8)$ & $49.95(43.8-56.0)$ & 155.3 \\
\hline & & 135 & 100 & $14.17 \pm 2.53$ & $40.77(33.4-48.1)$ & $57.8(51.2-64.3)$ & 190.2 \\
\hline & & 160 & 100 & $17.13 \pm 3.05$ & $47.45(38.6-56.3)$ & $68.0(60.1-75.9)$ & 177.1 \\
\hline & & 180 & 100 & $17.90 \pm 3.12$ & $49.65(40.4-58.9)$ & $71.14(62.9-79.3)$ & 177.9 \\
\hline & $95 \mathrm{ppm}$ & 8 & 100 & $4.59 \pm 0.78$ & $10.13(7.7-12.5)$ & $15.64(13.5-17.7)$ & 119.2 \\
\hline & & 31 & 100 & $6.13 \pm 1.01$ & $13.41(10.2-16.5)$ & $20.70(17.9-23.5)$ & 118.9 \\
\hline & & 65 & 100 & $5.68 \pm 0.99$ & $16.11(13.1-19.0)$ & $22.94(20.3-25.5)$ & 187.2 \\
\hline & & 90 & 100 & $11.37 \pm 1.98$ & $32.23(26.3-38.1)$ & $45.88(40.7-51.0)$ & 187.2 \\
\hline & & 135 & 100 & $13.35 \pm 2.33$ & $36.15(29.2-43.0)$ & $52.17(46.0-58.3)$ & 171.1 \\
\hline & & 160 & 100 & $13.98 \pm 2.42$ & $40.13(32.9-47.3)$ & $56.92(50.5-63.3)$ & 188.8 \\
\hline & & 180 & 100 & $15.37 \pm 2.71$ & $44.26(36.30-52.2)$ & $62.7(55.6-69.8)$ & 189.6 \\
\hline & $125 \mathrm{ppm}$ & 8 & 100 & $3.77 \pm 0.64$ & $9.81(7.8-11.8)$ & $14.35(12.6-16.0)$ & 160.7 \\
\hline & & 31 & 100 & $5.58 \pm 0.95$ & $12.45(9.5-15.3)$ & $19.15(16.6-21.7)$ & 120.3 \\
\hline & & 65 & 100 & $5.81 \pm 1.00$ & $13.21(10.2-16.2)$ & $20.19(17.5-22.8)$ & 124.3 \\
\hline & & 90 & 100 & $11.62 \pm 2.00$ & $26.42(20.4-32.4)$ & $40.38(35.0-45.7)$ & 124.3 \\
\hline & & 135 & 100 & $12.17 \pm 2.08$ & $29.89(23.6-36.1)$ & $44.51(38.9-50.0)$ & 143.0 \\
\hline & & 160 & 100 & $13.42 \pm 2.34$ & $35.23(28.2-42.2)$ & $51.34(45.2-57.5)$ & 162.5 \\
\hline & & 180 & 100 & $13.69 \pm 2.39$ & $37.31(30.2-44.4)$ & $53.75(47.5-60.0)$ & 173.3 \\
\hline
\end{tabular}

\footnotetext{
${ }^{a}$ DAT, days after treatment.
}

${ }^{b} 95 \%$ FL, $95 \%$ fiducial limits. 
Table 4. Toxicity of bifenthrin treated soil to termites at different time intervals over a period of $180 \mathrm{~d}$ after the initial application

\begin{tabular}{|c|c|c|c|c|c|c|c|}
\hline Termiticide & $\begin{array}{c}\text { Concn } \\
(\mu \mathrm{g} / \mathrm{g} \text { soil })\end{array}$ & $\mathrm{DAT}^{a}$ & $n$ & $\begin{array}{l}\text { Slope } \pm \\
\text { SE }\end{array}$ & $\mathrm{LT}_{50}(95 \% \mathrm{FL})^{2}(\mathrm{~h})$ & $\begin{array}{c}\mathrm{LT}_{90}(95 \% \mathrm{FL}) \\
(\mathrm{h})\end{array}$ & $\chi^{2}$ \\
\hline \multirow[t]{21}{*}{ Bifenthrin } & $60 \mathrm{ppm}$ & 8 & 100 & $2.40 \pm 0.40$ & $5.76(4.5-7.0)$ & $8.65(7.5-9.7)$ & 140.3 \\
\hline & & 32 & 100 & $4.03 \pm 0.70$ & $9.33(7.2-11.4)$ & $14.17(12.3-16.0)$ & 128.8 \\
\hline & & 65 & 100 & $5.55 \pm 0.94$ & $12.65(9.8-15.5)$ & $19.33(16.8-21.8)$ & 125.1 \\
\hline & & 90 & 100 & $6.47 \pm 1.15$ & $16.41(13.0-19.7)$ & $24.18(21.19-27.1)$ & 151.4 \\
\hline & & 135 & 100 & $7.40 \pm 1.31$ & $19.03(15.2-22.8)$ & $27.92(24.5-31.3)$ & 155.1 \\
\hline & & 160 & 100 & $8.50 \pm 1.51$ & $21.36(16.9-25.7)$ & $31.58(27.6-35.5)$ & 149.9 \\
\hline & & 180 & 100 & $9.34 \pm 1.61$ & $22.72(17.9-27.5)$ & $33.94(29.7-35.7)$ & 142.0 \\
\hline & $90 \mathrm{ppm}$ & 8 & 100 & $2.58 \pm 0.43$ & $5.57(4.2-6.9)$ & $8.67(7.5-9.8)$ & 113.2 \\
\hline & & 32 & 100 & $3.89 \pm 0.68$ & $8.33(6.30-10.35)$ & $13.01(11.2-14.8)$ & 112.1 \\
\hline & & 66 & 100 & $5.34 \pm 0.92$ & $11.64(8.8-14.4)$ & $18.06(15.6-20.5)$ & 115.7 \\
\hline & & 90 & 100 & $6.64 \pm 1.16$ & $14.69(11.2-18.1)$ & $22.67(19.6-25.7)$ & 120.4 \\
\hline & & 135 & 100 & $7.55 \pm 1.32$ & $17.44(13.5-21.3)$ & $26.50(23.0-29.9)$ & 130.3 \\
\hline & & 160 & 100 & $7.65 \pm 1.36$ & $18.65(14.7-22.6)$ & $27.84(24.3-31.3)$ & 142.6 \\
\hline & & 180 & 100 & $8.17 \pm 1.44$ & $20.60(16.3-24.8)$ & $30.42(26.7-34.1)$ & 150.6 \\
\hline & $120 \mathrm{ppm}$ & 8 & 100 & $2.60 \pm 0.43$ & $5.15(3.8-6.5)$ & $8.28(7.1-9.4)$ & 100.8 \\
\hline & & 31 & 100 & $4.08 \pm 0.71$ & $7.97(5.8-10.0)$ & $12.87(11.00-14.7)$ & 96.5 \\
\hline & & 65 & 100 & $4.45 \pm 0.77$ & $9.14(6.8-11.4)$ & $14.50(12.4-16.5)$ & 104.2 \\
\hline & & 90 & 100 & $5.58 \pm 0.98$ & $12.16(9.2-15.0)$ & $18.87(16.3-21.43)$ & 116.7 \\
\hline & & 135 & 100 & $6.96 \pm 1.21$ & $15.30(11.7-18.9)$ & $23.65(20.4-26.8)$ & 119.9 \\
\hline & & 160 & 100 & $7.71 \pm 1.35$ & $17.05(13.0-21.0)$ & $26.31(22.7-29.8)$ & 120.5 \\
\hline & & 180 & 100 & $7.99 \pm 1.39$ & $17.92(13.8-22.0)$ & $27.52(23.9-31.1)$ & 122.5 \\
\hline
\end{tabular}

\footnotetext{
${ }^{a}$ DAT, days after treatment.
}

${ }^{b} 95 \%$ FL, $95 \%$ fiducial limits.

Bioavailability of Termiticides. The regression analysis between the $\log _{10}$-transformed values of recovered termiticides (micrograms per gram of soil) and $\log _{10} \mathrm{LT}_{90}$ values (hours), resulted in regression values $\left(R^{2}\right)$ ranging between 0.87 and 0.98 for all the tested termiticides and concentrations (Figs. 4-6). For imidacloprid (100 ppm), fipronil (125 ppm), and bifenthrin $(120 \mathrm{ppm})$, the slopes of the regression equations were $-4.0,-6.8$, and -4.1 , respectively. However, at the lowest applied concentrations of imidacloprid (50 ppm), fipronil (60 ppm), and bifenthrin $(60 \mathrm{ppm})$, the slopes of the regression equations were
$-2.6,-3.1$, and -2.3 , respectively. This indicated that the termite mortality was higher at higher concentrations due to enhanced bioavailability of the applied termiticides.

\section{Discussion}

Our recovery rates and extraction efficiencies were consistent with those reported by Bobe et al. 1998 ( $85 \pm 5 \%$ for fipronil), and Baskaran et al. 1999 (81.6 \pm $2.4 \%$ for bifenthrin and $85.2 \pm 2.4 \%$ for imidacloprid). Thus, the decrease in amount of termiticides recov-

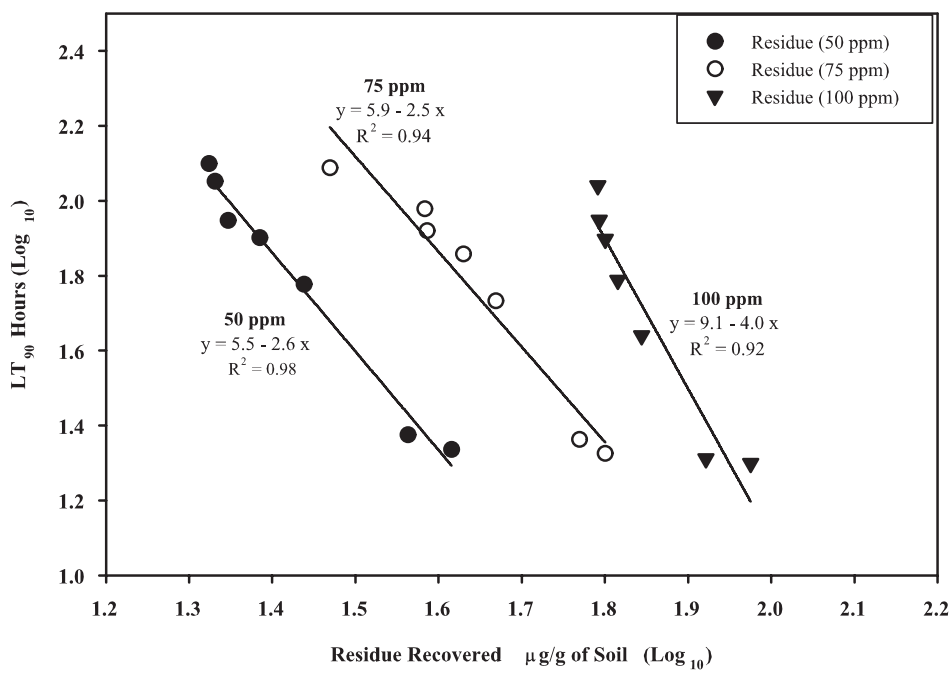

Fig. 4. Relationship between the amounts of imidacloprid recovered at different intervals and $\mathrm{LT}_{90}$ values for termites exposed to these samples. The regression equations between different concentrations and $\mathrm{LT}_{90}$ values are provided next to each regression line: $50 \mathrm{ppm}: R^{2}=0.98, F=290.3 \mathrm{df}=1,5, P<0.001 ; 75 \mathrm{ppm}: R^{2}=0.94, F=85.0, \mathrm{df}=1,5, P<0.001$; and 100 ppm: $R^{2}=0.92, F=60.0, \mathrm{df}=1,5, P<0.001$. 


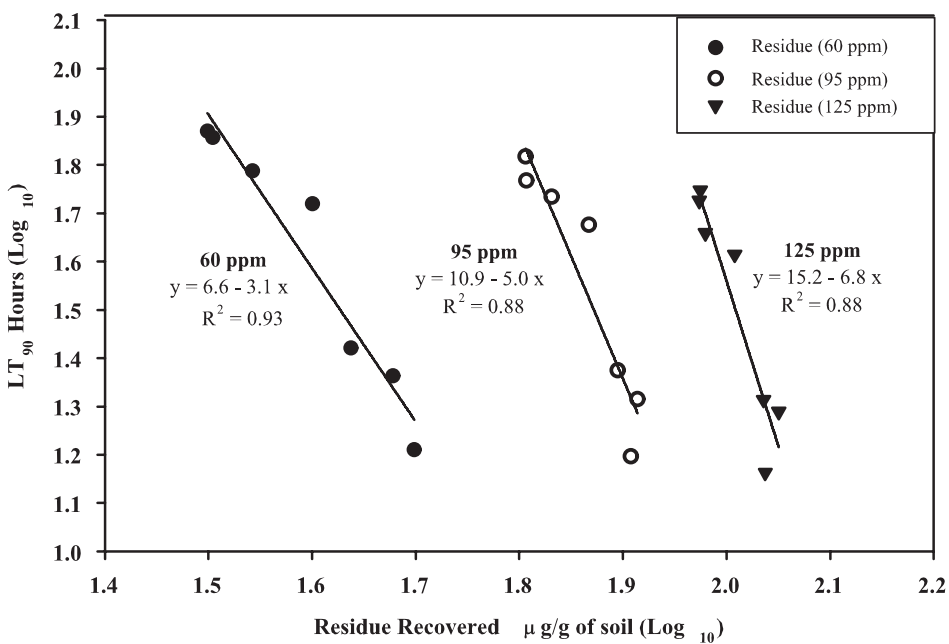

Fig. 5. Relationship between the amounts of fipronil recovered at different intervals and $\mathrm{LT}_{90}$ values for termites exposed to these samples. The regression equations between different concentrations and $\mathrm{LT}_{90}$ values are provided next to each regression line: $60 \mathrm{ppm}: R^{2}=0.93, F=72.7 \mathrm{df}=1,5, P<0.001 ; 95 \mathrm{ppm}: R^{2}=0.88, F=38.3$, df $=1,5, P<0.001$; and 125 ppm: $R^{2}=0.88, F=38.7$, df $=1,5, P<0.001$.

ered over time from soil samples was due to degradation only and was not due to a time-dependent adsorption phenomenon. Baskaran et al. (1999) reached similar conclusions in their study with bifenthrin, imidacloprid, and chlorpyrifos.

The initial concentrations of the termiticides applied to the soil affected the degradation rates and consequently the half-lives based on these degradation rates were significantly different. It has been suggested that the prolonged persistence of the insecticides when applied at higher concentrations was associated with a temporary decrease in bacterial and fungus numbers resulting in a prolonged inhibition of soil dehydrogenase and esterase activities (Felsot and Dzantor 1995).

Few data are available on the degradation of fipronil (Bobe et al. 1997) and even less so for the rates applied as termiticides. When applied at field application rates (8 g $[\mathrm{AI}] / \mathrm{ha}), 75 \%$ of the fipronil degraded within $3 \mathrm{~d}$, and the four metabolites were detected (Bobe et al. 1998). Fipronil when applied at termiticidal rates did not show much degradation, and no metabolites were detected in our residue analysis even after $180 \mathrm{~d}$. We considered fipronil residue recoveries as "toxic total" (fipronil + metabolites A, B, C) as reported by Bobe et al. (1998) at field application rates.

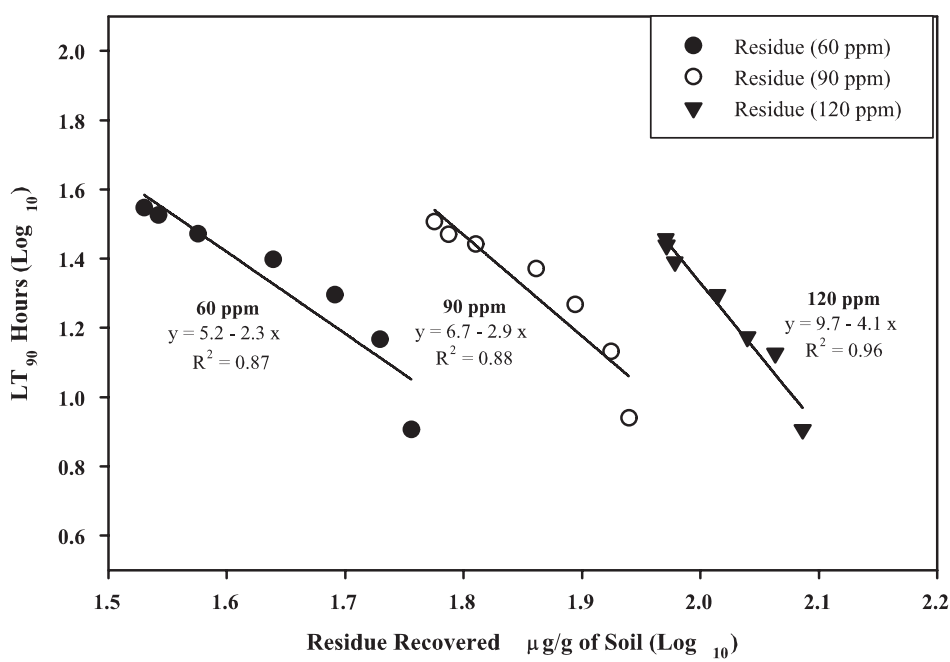

Fig. 6. Relationship between the amounts of bifenthrin recovered at different intervals and $\mathrm{LT}_{90}$ values for termites exposed to these samples. The regression equations between different concentrations and $\mathrm{LT}_{90}$ values are provided next to each regression line: $60 \mathrm{ppm}: R^{2}=0.87, F=34.9$, $\mathrm{df}=1,5, P=0.002 ; 75 \mathrm{ppm}: R^{2}=0.88, F=37.7 .0, \mathrm{df}=1,5, P<0.001$; and 120 ppm: $R^{2}=0.96, F=121.0, \mathrm{df}=1,5, P<0.001$ 
Differences in the initial application rates of termiticides and chemical and physical properties of the soil affect degradation rates. In the current study, because the insecticides were applied to the soil under similar laboratory incubation conditions, differences in degradation rates were more likely due to the chemical and physical properties of the insecticides. The degradation of these insecticides followed a linear pattern initially, but it became more flattened toward the end (Figs. 1-3). This suggested that the initial degradation rates were much higher, they slowed over time. The slowing degradation rates may have affected the estimated half-lives of the termiticides and their availability to the termites in the soil. Bobe et al. (1998), Baskaran et al. (1999), Racke et al. (1994), and Su et al. (1999) observed similar degradation trends in their studies.

There was an inverse relationship between the initial applied concentrations of all three termiticides in our study and their $\mathrm{LT}_{50}$ and $\mathrm{LT}_{90}$ values against $R$. flavipes. Bioavailability of the termiticides over time was higher at higher concentrations. The greater bioavailability of the termiticides may explain similar trends observed in previous studies (Edwards et al. 1957, Peterson et al. 1971, Smith and Rust 1992, Forschler and Townsend 1996, Ramakrishnan et al. 2000). However, bioassays with treated soil demonstrated that the differences in $\mathrm{LT}_{50}$ and $\mathrm{LT}_{90}$ were partly explained by the differential availability of termiticides in soil because bioactivity varies among soil types. Felsot and Lew (1989) suggested that partitioning of the insecticides between soil organic matter and soil solution (i.e., the sorption process, which is inversely related to the water solubility), affects the availability of the insecticide to target organisms. Because termiticide application rates are very high in comparison to rates used in agriculture, the bioavailability and the efficacy of relatively water-soluble termiticides such as imidacloprid will not be significantly lower than other classes of less soluble compounds (e.g., pyrethroids and phenyl pyrazoles). Oi (1999) demonstrated increased adsorption of imidacloprid in soil with time, which resulted in increased $K_{\mathrm{oc}}$ values. However, over time and depending on the degradation rates, the concentration of the applied termiticides might reduce to levels at which the bioavailability decreases considerably providing only sublethal or no effects on termites.

Fipronil exhibits low water solubility $(1.9 \mathrm{mg} /$ liter $)$ at $20^{\circ} \mathrm{C}$ in distilled water. At low rates in soil, it has low soil affinity, due to strong competition from the aqueous phase. Adsorption increases as concentration increases (Bobe et al. 1997). However, at termiticide application rates of $0.06-0.125 \%$, the adsorption process exhibits a reverse phenomenon, whereby there is a decrease in adsorption coefficient with an increase in concentration (Kamble and Saran 2005). The result is that over a certain range of concentration, more fipronil molecules will be present in the aqueous phase. In the case of fipronil it was also demonstrated that there was a significant decrease in adsorption coefficient as the soil organic matter and clay content decreased (Bobe et al. 1997). This explains more bioavailability of the fipronil in soils with lower organic matter because of the small amount of organic phase available for fipronil molecules. Lower water solubility of fipronil offers a lower leaching potential as demonstrated by Bobe et al. (1997) and a higher persistence, the latter being more important for a durable termiticide treatment.

Bifenthrin has low water solubility $(0.1 \mathrm{mg} /$ liter $)$, is strongly adsorbed $\left(\mathrm{K}_{\mathrm{oc}} 1,000,000\right.$, Xia and Brandenburg 2000) in soil, and shows no leaching potential. However, there was some increased efficacy against mole cricket when golf fields were watered immediately before or after application (Xia and Brandenburg 2000). Bifenthrin molecules are tightly bound to soil particles and may not be competitively absorbed by termite body. But even in a tightly bound condition, it has been demonstrated previously (Smith and Rust 1992) that termites were quickly killed at $20 \%$ soil moisture. Increased clay content increases the toxicity of certain pyrethroids, such as cypermethrin (Smith and Rust 1993). Cypermethrin and clay apparently interacted creating a formulation similar to a wettable powder (Smith and Rust 1993). Such wettable powder may have increased affinity to the nonpolar termite integument and could easily penetrate the termite integument. Because bifenthrin and cypermethrin belong to the same class of insecticides, the higher clay content in the soil used in current study, $(>25 \%)$ might explain higher toxicity of bifenthrin compared with fipronil and imidacloprid. However, some background information about the behavior of bifenthrin in soil and its toxic action on insects will help us in understanding the bioavailability of bifenthrin to termites. Smith and Rust (1990) reported the high mortality rate when termites were directly exposed to soil treated with bifenthrin. In their direct exposure studies, bifenthrin had the greatest activity compared with other pyrethroids, because as little as 1 ppm killed all the insects within $3 \mathrm{~h}$. It also was observed that pyrethroids bifenthrin, cypermethrin, and permethrin acted much faster than chlorpyrifos and chlordane. In their tunneling study, termites did not tunnel into soil treated with formulated bifenthrin even at the lowest concentration of $1 \mathrm{ppm}$ (wt:wt) due to repellency against bifenthrin. Certain termiticides, especially pyrethroids, were reported to be repellent to termite workers ( $\mathrm{Su}$ et al. 1982, Jones 1989, Smith and Rust 1990, Rust and Smith 1993). Su and Scheffrahn (1990) found that nine different pyrethroids were repellent at sublethal doses.

The differential bioavailability in different soil types may affect the field performance of a termiticide over longer periods than tested in our study. Therefore, termiticide soil bioassay must be reported in relation to soil type (Forschler and Townsend 1996). The particular mode of action of the various termiticides used in this research reaffirms what we presently know about the speed in which they knock down insects in general. The response time to intoxication was observed in a descending order of pyrethroids $<$ phenyl pyrazoles $<$ chloronicotinyls. Further knowledge 
about efficacy and bioavailability of the newer compounds like imidacloprid and fipronil will be more relevant in terms of understanding their ability to protect treated structures over time. We did not test for any microbial activity in our soil samples but microorganisms play a major role in the degradation of many pesticides (Harris et al. 1988), yet little is known about the type of microbes involved specifically. The knowledge about the abundance and survival of such microorganisms will definitely provide us more information about the degradation of new generation termitcides in different soil types and locations.

\section{Acknowledgments}

We thank Blair Siegfried for suggestions in original draft. This is published as paper no. 1268, Department of Entomology, University of Nebraska, Lincoln, NE.

\section{References Cited}

Austin, J. W. 1999. Bioavailability and uptake of selected termiticides to control the eastern subterranean termite, Reticulitermes flavipes (Kollar) (Isoptera: Rhinotermitidae). M.S. thesis, University of Nebraska, Lincoln, NE.

Baskaran, S., R. S. Kookana, and R. Naidu. 1999. Degradation of bifenthrin, chlorpyrifos, and imidacloprid in soil and bedding materials at termiticidal application rates. Pestic. Sci. 55: 1222-1228.

Bobe, A., C. M. Coste, and J. F. Copper. 1997. Factors influencing the adsorption of fipronil on soils. J. Agric. Food Chem. 45: 4681-4865.

Bobe, A., J. F. Cooper, C. M. Coste, and M. A. Muller. 1998. Behavior of fipronil in soil under sahelian plain field conditions. Pestic. Sci. 52: 275-281.

Chapman, R. A., C. M. Tu, C. R. Harris, and D. Dubois. 1982. Biochemical and chemical transformations of terbufos, terbufos sulfoxide, and terbufos sulfone in natural and sterile, mineral and organic soil insecticides contamination residues. J. Econ. Entomol. 75: 955-960.

Curl, G. 2004. Pumped-up termite market. Pest. Contr. Tech. 32: 26, 28, 33 .

Felsot, A. S., and A. Lew. 1989. Factors affecting bioactivity of soil insecticides: relationships among uptake, desorption, and toxicity of carbofuran and terbufos. J. Econ. Entomol. 82: 389-395.

Felsot, A. S., and E. K. Dzantor. 1995. Effect of alachlor concentration and an organic amendment on soil dehydrogenase activity and pesticide degradation rate. Environ. Toxicol. Chem. 14: 23-28.

Forschler, B. T., and M. L. Townsend. 1996. Mortality of eastern subterranean termites (Isoptera: Rhinotermitidae), exposure to four soils treated with termiticides. J. Econ. Entomol. 89: 678-681.

Gold, R. E., A. A. Collins, B. M. Pawson, and H. N. Howell, Jr. 1994. Termiticide technology-the isophenfos dilemma. Technol. J. Franklin Inst. 331(A): 189-198.

Gold, R. E., H. N. Howell, Jr., B. M. Pawson, M. S. Wright, and J. C. Lutz. 1996. Persistence and bioavailability of termiticides to subterranean termites (Isoptera: Rohinotermitdiae) from soil types and locations in Texas. Sociobiology 28: 337-364.

Hainzl, D., and J. E. Casida. 1996. Fipronil insecticide: novel photochemical desulfinylation with retention of neurotoxicity. Proc. Natl. Acad. Sci. U.S.A. 93: 12764-12767.
Harris, C. R. 1972. Factors influencing the effectiveness of soil insecticides. Annu. Rev. Entomol. 17: 177-198.

Harris, C. R., R. A. Chapman, R. F. Morris, and A. B. Stevenson. 1988. Enhanced soil microbial degradation of carbofuran and fensulfothion-a factor contributing to the decline in effectiveness of some soil insect control programs in Canada. J. Environ. Sci. Health B 23: 301-316.

Helling, C. S., and B. C. Turner. 1970. Movement of Striazine herbicides in soils. Residue Rev. 32: 175-210.

Ibrahim, S. A., G. Henderson, and H. Fei. 2003. Toxicity, repellency and horizontal transmission of fipronil in the Formosan subterranean termite (Isoptera: Rhinotermitidae). J. Econ. Entomol. 96: 461-467.

Jones, S. C. 1989. How toxic and repellent are soil insecticides to subterranean termites? Pest Manag. 8: 16-19.

Kamble, S. T., and R. K. Saran. 2005. Effect of concentration on the adsorption of three termiticides in soil. Bull. Environ. Contam. Toxicol. 75: 1077-1085.

Macalady, D. L., and N. L. Wolfe. 1983. New perspectives on the hydrolytic degradation of the organophosphorothioate insecticide chlorpyrifos. J. Agri. Food. Chem. 31: $1139-1147$.

McCall, P. J., R. L. Swann, D. A. Laskowski, S. A. Vrona, S. M. Unger, and H. J. Dishburger. 1979. Prediction of chemical mobility in soil from sorption coefficients, pp. 49-58. Proc. Aquatic Toxic Hazard. Assess. ASTM, Philadelphia, PA.

Oi, M. 1999. Time-dependent sorption of imidacloprid in two different soils. J. Agric. Food Chem. 47: 327-332.

Osbrink, W.L.A., M. L. Cornelius, and A. R. Lax. 2005. Effect of imidacloprid soil treatments on occurrence of Formosan subterranean termites (Isoptera: Rhinotermitidae) in independent monitors. J. Econ. Entomol. 98: $2160-2168$.

Peterson, J. R., R. S. Adams, and L. K. Cutkomp. 1971. Soil properties influencing DDT bioactivity. Soil Sci. Soc. Am. Proc. 35: 72-78.

Placke, F. J., and E. Weber. 1993. Method of determining imidacloprid residues in plant materials. Pflanzenschutz Nachrichten Bayer 46: 109-182.

Poole, C. F., and S. K. Poole. 1997. Chromatography today, pp. 90-94. Elsevier B.V., Amsterdam, The Netherlands.

Potter, M. F., and A. E. Hillery. 2002. Exterior-targeted liquid termiticides: an alternative approach to managing subterranean termites (Isoptera: Rhinotermitidae) in buildings. Sociobiology 39: 373-405.

Racke, K. D., D. D. Fontaine, R. N. Yoder, and J. R. Miller. 1994. Chlorpyrifos degradation in soil at termiticidal application rates. Pestic. Sci. 42: 43-51.

Ramakrishnan, R., D. R. Suiter, C. H. Nakatsu, and G. W. Bennett. 2000. Feeding inhibition and mortality in $R e$ ticulitermes flavipes (Isoptera: Rhinotermitidae) after exposure to imidacloprid-treated soils. J. Econ. Entomol. 93: $422-428$.

Remmen, L. N., and N.-Y. Su. 2005a. Time trends in mortality for thiamethoxam and fipronil against Formosan subterranean termites and eastern subterranean termites (Isoptera: Rhinotermitidae). J. Econ. Entomol. 98: 911915.

Remmen, L. N., and N.-Y. Su. 2005b. Tunneling and mortality of eastern and Formosan subterranean termites (Isoptera: Rhinotermitidae) in sand treated with thiamethoxam or fipronil. J. Econ. Entomol. 98: 906-910.

Rust, M. K., and J. L. Smith. 1993. Toxicity and repellency of components in formulated termiticides against western subterranean termites (Isoptera: Rhinotermitidae). J. Econ. Entomol. 86: 1131-1135. 
Rust, M. K., and R. K. Saran. 2006. The toxicity, repellency, and transfer of chlorfenapyr against western subterranean termites (Isoptera: Rhinotermitidae). J. Econ. Entomol. 99: 864-872.

Saran, R. K., and M. K. Rust. 2007. The toxicity, uptake, and transfer efficiency of fipronil in western subterranean termites (Isoptera: Rhinotermitidae). J. Econ. Entomol. 100: 495-508.

SAS Institute. 2000. SAS procedures guide for personal computers. SAS Institute, Cary, NC.

Shelton, T. G., and J. K. Grace. 2003. Effects of exposure duration on transfer of nonrepellent termiticides among workers of Coptotermes formosanus Shiraki (Isoptera: Rhinotermitidae). J. Econ. Entomol. 96: 456-460.

Simmons, K. A., A. C. Lew, I. R. Silverman, and S. F. Ali. 1992. Predicting the activity of soil-applied insecticides from their physiochemical properties. J. Agric. Food Chem. 40: 1432-1436.

Smith, J. L., and M. K. Rust. 1990. Tunneling response and mortality of western subterranean termite (Isoptera: Rhinotermitidae) to soil treated with termiticides. J. Econ. Entomol. 83: 1395-1401.

Smith, J. L., and M. K. Rust. 1992. Activity and water induced movement of termiticides in soil. J. Econ. Entomol. 85: $430-434$.

Smith, J. L., and M. K. Rust. 1993. Cellulose and clay in sand affects termiticide treatments. J. Econ. Entomol. 86: 53-60.

Snyder, T. E. 1954. Order Isoptera. The termites of the United States and Canada. National Pest Control Association, New York.

Steinwandter, H. 1992. Development of microextraction methods in residue analysis, pp. 3-50. In T. Cairns and J. Sherma [eds.], Emerging strategies for pesticide analysis. CRC, Boca Raton, FL.
Su, N. Y. 2005. Response of the Formosan subterranean termites (Isoptera: Rhinotermitidae) to baits or nonrepellent termiticides in extended foraging arenas. J. Econ. Entomol. 98: 2143-2152.

Su, N. Y., M. Tamashiro, J. R. Yates, and M. I. Haverty. 1982. Effect of behavior on the evaluation of insecticides for prevention of or remedial control of the Formosan subterranean termite Coptotermes formosanus, wood pest. J. Econ. Entomol. 75: 188-193.

Su, N. Y., and R. H. Scheffrahn. 1990. Comparison of eleven soil termiticides against the Formosan subterranean termite and eastern subterranean termite (Isoptera: Rhinotermitidae). J. Econ. Entomol. 83: 1918-1924.

Su, N. Y., and R. H. Scheffrahn. 1998. A review of subterranean termite control practices and prospects for integrated pest management programs. Integrated Pest Manage. Rev. 3: 1-13.

Su, N. Y., R. H. Scheffrahn, and P. M. Ban. 1993. Barrier efficacy of pyrethroid and organophosphate formulations against subterranean termites (Isoptera: Rhinotermitidae). J. Econ. Entomol. 86: 772-776.

Su, N. Y., P. M. Ban, V. Chew, and R. H. Scheffrahn. 1999. Size and edge effects of concrete plots on chlorpyrifos degradation in sub-slab sand. J. Econ. Entomol. 92: 409415.

Tashiro, H. S., and R. J. Khur. 1978. Distribution and persistence of chlorpyrifos and diazinon (insecticides) applied to turf. Bull. Environ. Contam. Toxicol. 20: 652-656.

Xia, Y., and L. Brandenburg. 2000. Effect of irrigation on the efficacy of insecticides for controlling two species of mole crickets (Orthoptera: Gryllotalpidae) on Golf Courses. Hortic. Entomol. 93: 852-857.

Received 13 February 2007; accepted 5 April 2008. 